\title{
PENGARUH PENGGUNAAN MEDIA PEMBELAJARAN POWER POINT TERHADAP HASIL BELAJAR SISWA KELAS XI SMA
}

\author{
Suryanti \\ Program Studi Pendidikan Matematika, Fakultas Keguruan dan Ilmu Pendidikan \\ Universitas Pancasakti Makassar \\ e-mail: anthysuryanti43@gmail.com
}

\begin{abstract}
ABSTRAK
Penelitian ini bertujuan untuk mengetahui pengaruh penggunaan media pembelajaran terhadap hasil belajar siswa pada pada pembelajaran matematika di SMA 17 Makassar. Dalam penelitian ini menggunakan pendekatan kuantitatif, jenis penelitian yang digunakan adalah ex-post facto. Sedangkan instrumen dalam pengumpulan data peneliti menggunakan angket untuk mengukur penggunaan media pembelajaran, dan dokumentasi digunakan untuk mengukur hasil belajar siswa. Setelah dilaksanakan pengujian menggunakan regresi linier sederhana hasil penelitian menunjukkan bahwa: Ada pengaruh yang signifikan antara penggunaan media pembelajaran power point terhadap hasil belajar siswa pada pembelajaran matematika di SMAN 17 Makassar yang ditunjukkan dari thitung $>$ tabel $(2,396>2,017)$. Nilai signifikansi $t$ untuk variabel penerapan model diskusi pemahaman teks adalah 0,021 dan nilai tersebut lebih kecil dari pada probabilitas $0,021(0,021<0,05)$. The significance value of $t$ for the variable application of the discussion model for text understanding is 0.021 and this value is smaller than the probability $0.021(0.021<0.05)$.
\end{abstract}

Kata Kunci: media pembelajaran, power point, hasil belajar

\begin{abstract}
This study aims to determine the effect of using instructional media on student learning outcomes in mathematics learning at SMA 17 Makassar. In this study using a quantitative approach, the type of research used is ex-post facto. While the instruments in data collection researchers used a questionnaire to measure the use of learning media, and documentation was used to measure student learning outcomes. After testing using simple linear regression, the results showed that: There is a significant influence between the use of power point learning media on student learning outcomes in mathematics learning at SMAN 17 Makassar as shown from thitung $>t_{\text {tabel }}(2,396>2,017)$.
\end{abstract}

Keywords: learning Media, power point, learning outcomes

\section{A. PENDAHULUAN}

Pendidikan merupakan bagian yang sangat penting bagi kehidupan manusia, sebab dengan pendidikan manusia dapat hidup sesuai dengan tujuan dan fungsinya sebagai manusia. Pendidikan juga mempunyai peranan penting dalam membangun negeri kita, karena dengan 
pendidikan kita dapat menghasilkan orang-orang yang memiliki kemampuan untuk membangun negeri kita lebih baik ke depannya.

Seiring dengan perkembangan teknologi, dunia pendidikan juga mengalami perkambangan. Salah satunya adalah dengan penggunaan media pembelajaran. Pada zaman dahulu sumber belajar hanya dari buku dan guru sendiri, sedangkan media pembelajaran hanya berupa papan tulis dan spidol. Sementara pada era modern ini sumber belajar bukan hanya dari buku dan guru tetapi peserta didik dapat mendapatkan materi dari internet sedangkan media pembelajaran bisa menggunakan komputer.

Pemanfaatan komputer sebagai media pembelajaran semakin mendorong upaya pembaharuan dalam kegiatan pemebelajaran di sekolah. Para guru sebagai tenaga pendidik dituntut agar mampu menguassai komputer sebagai media pembelajaran. Untuk itu guru harus memiliki pemahaman dan pengetahuan yang cukup tentang media pembelajaran, yang meliputi:

a. Media sebagai alat komunikasi guna lebih mengefektifkan proses belajar mengajar

b. Fungsi media dalam rangka mencapai tujuan pendidikan

c. Seluk-beluk proses belajar

d. Hubungan antara metode mengajar dan media pendidikan

e. Nilai atau manfaat media pendidikan dalam pengajaran

f. Pemilihan dan penggunaan media pendidikan

g. Berbagai jenis alat dan teknik media pendidikan

h. Media pendidikan dalam setiap mata pelajaran

i. Usaha inovasi dalam media pendidikan

Berbicara media pembelajaran sangat banyak jenisnya, mulai dari media gambar, media video, serta media power point. Media pembelajaran adalah bagian yang tidak terpisahkan dari proses belajar mengajar demi tercapainya tujuan pendidikan pada umumnya dan tujuan pembelajaran di sekolah pada khususnya. Adanya media pendidikan akan mempermudah guru dalam menjelaskan pelajaran kepada siswa sehingga siswa juga mudah menangkap serta memahami materi yang telah disampaikan oleh guru. Jadi media pembelajaran mempunyai peranan penting dalam kegiatan belajar dan mengajar. Oleh karena itu penulis tertarik untuk meneliti tentang pengaruh penggunaan media pembelajaran power point terhadap hasil belajar matematika siswa SMA.

\section{B. METODE}

Penelitian ini menggunakan penelitian ex-post facto dengan metode penelitian korelasional dan teknik analisis korelasional. Penelitian ex-post facto merupakan penelitian dimana variabelvariabel bebas telah terjadi ketika peneliti mulai dengan pengamatan variabel terikat dalam 
suatu penelitian. Jenis penelitian korelasional dipilih karena disesuaikan dengan tujuan penelitian ini yaitu untuk mengetahui hubungan, dilanjutkan menghitung (varians) pengaruh variabel bebas penggunaan media pembelajaran terhadap hasil belajar. Kedua variabel tersebut dianggap memiliki hubungan asimetris. Hubungan asimetris adalah hubungan dimana mendiskripsikan bagaimana suatu variabel dapat mempengaruhi variabel yang lain (hubungan stimulus-respon). Jadi penelitian korelasi merupakan salah satu bagian penelitian expost facto karena biasanya peneliti tidak memanipulasikan keadaan variabel yang ada dan langsung mencari keberadaan hubungan dan tingkat hubungan variabel yang direfleksikan dalam koefisien korelasi.

\section{HASIL DAN PEMBAHASAN}

Instrumen yang digunakan untuk mengukur penggunaan media power point yaitu berupa angket yang terdiri dari 8 item pertanyaan, yang masing-masing item pertanyaan mempunyai 4 alternatif jawaban dengan rentang skor 1 - 4. Skor harapan terendah adalah 8 sedangkan total skor 93 harapan tertinggi adalah 32.

Berdasarkan total skor harapan tersebut maka dapat ditentukan interval skor masingmasing kelas atau jenjang yang dapat menggambarkan penggunaan media power point yang terdiri dari empat kategori yang sudah ditentukan yaitu sangat tinggi, tinggi, cukup, dan kurang. Dengan demikian dapat diketahui klasifikasi deskriptif statistik tentang penggunaan media power point yang digunakan guru kelas XI IPA dalam pembelajaran matematika yang selanjutnya dianalisis dengan menggunakan program SPSS dan hasilnya adalah sebagai berikut:

Tabel 1.1 Deskripsi Penggunaan Media Power Point

\begin{tabular}{|c|c|c|c|c|c|c|c|c|}
\hline & $\mathrm{N}$ & $\begin{array}{l}\text { Rang } \\
\mathrm{e}\end{array}$ & $\begin{array}{c}\text { Minimu } \\
\mathrm{m}\end{array}$ & $\begin{array}{c}\text { Maximu } \\
\mathrm{m}\end{array}$ & $\begin{array}{c}\mathbf{k} / \\
\text { Suk } \\
\mathrm{m} \\
\end{array}$ & $\begin{array}{c}\text { Mea } \\
\mathrm{n}\end{array}$ & $\begin{array}{c}\text { Std. } \\
\text { Deviati } \\
\text { on }\end{array}$ & $\begin{array}{c}\text { Varianc } \\
\mathrm{e}\end{array}$ \\
\hline $\begin{array}{c}\text { POWER } \\
\text { POINT }\end{array}$ & 45 & \multirow[t]{2}{*}{18} & \multirow[t]{2}{*}{14} & \multirow[t]{2}{*}{32} & \multirow[t]{2}{*}{$\begin{array}{c}100 \\
1\end{array}$} & \multirow[t]{2}{*}{$\begin{array}{c}22.2 \\
4\end{array}$} & \multirow[t]{2}{*}{$\begin{array}{c}3.55 \\
6\end{array}$} & \multirow[t]{2}{*}{$\begin{array}{c}12.6 \\
43\end{array}$} \\
\hline $\begin{array}{c}\text { Valid N } \\
\text { (listwise) }\end{array}$ & 45 & & & & & & & \\
\hline
\end{tabular}

Berdasarkan tabel diatas, diperoleh hasil statistik deskriptif penggunaan media power point yang dikumpulkan dari responden sebanyak 45 secara kuantitatif menunjukkan skor minimum yang didapat adalah 14 dan skor total maksimumnya adalah 32 . Rentang jumlah skor maksimum (range) adalah $32-48=18$. Jumlah skor 1001, rata-rata 22,24 standar deviasi sebesar 3,556 dan variansi 12,643.

Dari hasil output diatas selanjutnya diberikan pengkategorisasi. peneliti membatasi deskripsi datanya dengan empat kategori yaitu kurang, cukup, tinggi dan sangat tinggi. Berikut deskripsi 
kategorisasi penggunaan media power point yang dianalisis dengan menggunakan program SPSS sebagai berikut.

Tabel 2. Kategorisasi Penggunaan Media Power Point

\begin{tabular}{ccccc}
\hline No & Kriteria & Interval & Frekuensi & $\begin{array}{c}\text { Prosentase } \\
(\%)\end{array}$ \\
\hline 1 & Sangat Tinggi & $32-40$ & 1 & $2,2 \%$ \\
\hline 2 & Tinggi & $23-31$ & 19 & $42,2 \%$ \\
\hline 3 & Cukup & $15-22$ & 24 & $53,3 \%$ \\
\hline 4 & Kurang & $6-14$ & 1 & $2,2 \%$ \\
\hline Total & & 45 & $100 \%$ \\
\hline
\end{tabular}

KRITERIA MEDIA POWER POINT

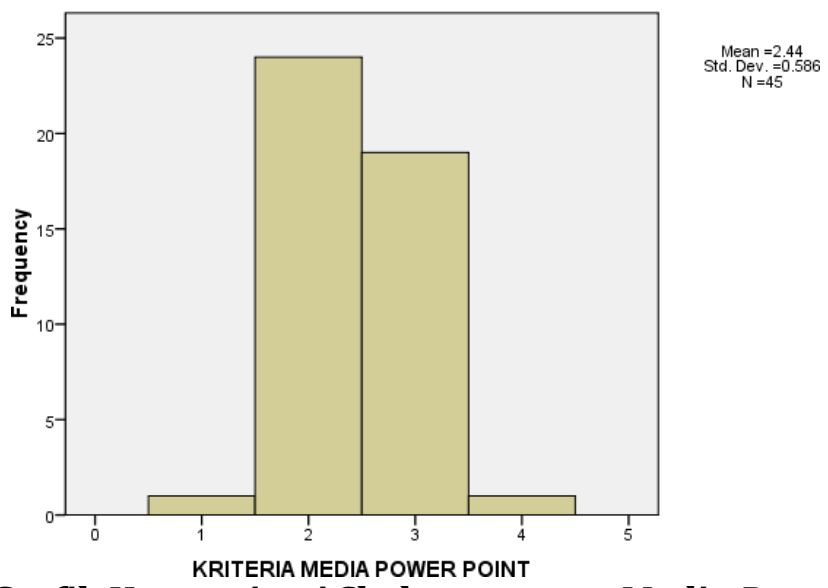

Gambar 1. Grafik Kategorisasi Skala nggunaan Media Power Point

Berdasarkan tabel dan grafik di atas menunjukkan frekuensi dan presentase mengenai tingkat penggunaan media power point yang digunakan guru kelas XI IPA di SMAN 17 Makassar adalah 1 responden $(2,2 \%)$ memiliki tingkat penggunaan media power point yang kurang, 24 responden (53,3 \%) memiliki tingkat penggunaan media power point yang cukup, 19 responden $(42,2 \%)$ memiliki tingkat penggunaan media power point yang tinggi dan 1 responden $(2,2 \%)$ memiliki tingkat penggunaan media power point yang sangat tinggi.

\section{ANALISIS DESKRIPTIF HASIL BELAJAR SISWA (Y)}

Tabel 3. Daftar Hasil Belajar Siswa

\begin{tabular}{cccc}
\hline No & Nilai & No & Nilai \\
\hline 1 & 86 & 24 & 91 \\
\hline 2 & 86 & 25 & 83 \\
\hline 3 & 86 & 26 & 87 \\
\hline 4 & 86 & 27 & 87 \\
\hline 5 & 86 & 28 & 84 \\
\hline
\end{tabular}




\begin{tabular}{llll}
\hline 6 & 86 & 29 & 87 \\
\hline 7 & 86 & 30 & 88 \\
\hline 8 & 86 & 31 & 86 \\
\hline 9 & 86 & 32 & 87 \\
\hline 10 & 83 & 33 & 88 \\
\hline 11 & 85 & 34 & 84 \\
\hline 12 & 87 & 35 & 86 \\
\hline 13 & 87 & 36 & 83 \\
\hline 14 & 85 & 37 & 85 \\
\hline 15 & 85 & 38 & 82 \\
\hline 16 & 85 & 39 & 83 \\
\hline 17 & 84 & 40 & 83 \\
\hline 18 & 85 & 41 & 82 \\
\hline 19 & 85 & 42 & 87 \\
\hline 20 & 87 & 43 & 84 \\
\hline 21 & 84 & 44 & 84 \\
\hline 22 & 83 & 45 & \\
\hline 23 & 85 & & \\
\hline
\end{tabular}

Berdasarkan hasil analisis dengan jumlah sampel 45 peserta didik pada kelas XI IPA maka peneliti dapat mengumpulkan data melalui nilai raport hasil belajar siswa semester ganjil 2019/2020 yang diberi oleh guru matematika. Berikut adalah hasil analisis deskriptif data hasil belajar siswa kelas XI SMAN 17 Makassar semester ganjil 2019/2020:

Tabel 4. Deskripsi Hasil Belajar Siswa

\begin{tabular}{|c|c|c|c|c|c|c|c|c|}
\hline & $\mathrm{N}$ & Range & $\begin{array}{l}\text { Minimu } \\
\mathrm{m}\end{array}$ & $\begin{array}{l}\text { Maximu } \\
\mathrm{m}\end{array}$ & Sum & $\begin{array}{l}\text { Mea } \\
\mathrm{n}\end{array}$ & $\begin{array}{c}\text { Std. } \\
\text { Deviati } \\
\text { on }\end{array}$ & Variance \\
\hline $\begin{array}{l}\text { HASIL } \\
\text { BELAJAR } \\
\end{array}$ & 45 & \multirow[t]{2}{*}{9} & \multirow[t]{2}{*}{82} & \multirow[t]{2}{*}{91} & \multirow{2}{*}{$\begin{array}{l}383 \\
9\end{array}$} & \multirow{2}{*}{$\begin{array}{l}85.3 \\
1\end{array}$} & \multirow{2}{*}{$\begin{array}{l}1.79 \\
4\end{array}$} & \multirow{2}{*}{$\begin{array}{l}3.21 \\
9\end{array}$} \\
\hline $\begin{array}{l}\text { Valid N } \\
\text { (listwise) }\end{array}$ & 45 & & & & & & & \\
\hline
\end{tabular}

Berdasarkan tabel diatas, diperoleh hasil statistik deskriptif dari 45 responden diperoleh skor minimum 82 , skor maksimum 91, sehingga range 91-82=9. Jumlah skor 3839, rata-rata 85,31, standar deviasi atau simpangan baku sebesar 1,794 dan variansi 3,219.

Dari hasil output diatas selanjutnya diberikan pengkategorisasian mengenai hasil belajar siswa pada pembelajaran pendidikan agama Islam. Dari data hasil tersebut, peneliti membatasi deskripsi datanya dengan empat kategori saja. Empat kategori tersebut yaitu kurang (6-14), cukup (15-22), tinggi (23-31) dan sangat tinggi (32-40). Berikut deskripsi pengkategorisasian hasil belajar siswa yang dianalisis dengan menggunakan program SPSS sebagai berikut: 
Tabel 5. Kategori Hasil Belajar Siswa

\begin{tabular}{ccccc}
\hline No & Kriteria & Interval & Frekuensi & $\begin{array}{c}\text { Prosentase } \\
(\%)\end{array}$ \\
\hline 1 & Sangat Tinggi & $91-93$ & 1 & $2,2 \%$ \\
\hline 2 & Tinggi & $88-90$ & 2 & $4,4 \%$ \\
\hline 3 & Cukup & $85-87$ & 27 & $60,1 \%$ \\
\hline 4 & Kurang & $82-84$ & 15 & $33,3 \%$ \\
\hline & & 45 & $100 \%$ \\
\hline
\end{tabular}

KRITERIA HASIL BELAJAR

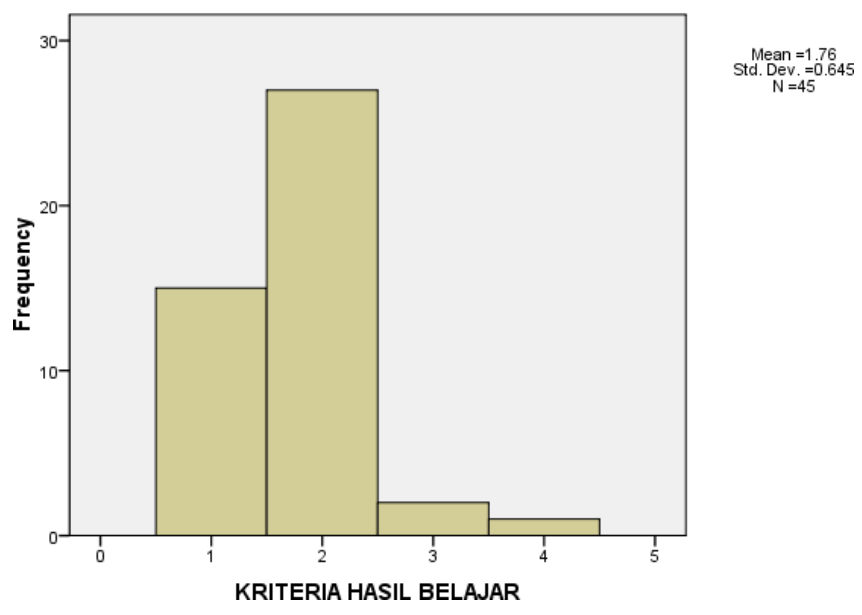

GAMBAR 2. GRAFIK KATEGORISASI SKALA HASIL BELAJAR SISWA

Dari tabel diatas menunjukkan bahwa 1 atau 2,2\% responden memiliki hasil belajar siswa dengan kriteria sangat tinggi, 2 atau 4,4\% responden memiliki hasil belajar dengan kriteria tinggi, 27 atau 60,1\% responden memiliki hasil belajar siswa dengan kriteria cukup, 15 atau $33,3 \%$ responden memiliki hasil belajar siswa dengan kriteria kurang.

Dengan demikian dapatlah dikatakan bahwa dari hasil penelitian ini menunjukkan adanya kecenderungan hasil belajar siswa berada pada kriteria cukup.

\section{UJI NORMALITAS}

Uji normalitas ini dimaksudkan untuk mengetahui bahwa distribusi penelitian tidak menyimpang secara signifikan dari distribusi normal. Cara untuk mengetahui nilai normalitas adalah dengan rumus Kolmogrof Smirnov yang dibantu menggunakan aplikasi SPSS

Tabel 6. Hasil Uji Normalitas Penggunaan Media Pembelajaraan Terhadap Hasil Belajar Siswa

\begin{tabular}{llr}
\hline & & $\begin{array}{c}\text { Unstandardi } \\
\text { zed } \\
\text { Residual }\end{array}$ \\
\hline $\mathrm{N}$ & Mean & 45 \\
\hline Normal Parameters $^{\mathrm{a}}$ & Std. Deviation & 1.79225623 \\
\hline
\end{tabular}




\begin{tabular}{llr}
\hline $\begin{array}{l}\text { Most Extreme } \\
\text { Differences }\end{array}$ & Absolute & .115 \\
\hline & Positive & .097 \\
\hline & Negative & -.115 \\
\hline Kolmogorov-Smirnov Z & & .770 \\
\hline Asymp. Sig. (2-tailed) & & .594 \\
\hline
\end{tabular}

Untuk menguji apakah sampel penelitian merupakan jenis distribusi normal dapat digunakan dengan teknik One Sample Kolmogrov- Smirnov Test. Data dikatakan normal apabila p $>$ 0,05. Dari hasil analisis diatas, menunjukkan sebaran skor variabel dukungan kecerdasan emosional dan hasil belajar kognitif adalah normal (KS-Z =0,770; $p=0,594)$. Data nilai signifikan lebih besar $(0,594>0,05)$. Jadi, dapat disimpulkan asumsi normalitas sebaran terpenuhi atau dikatakan berdistribusi normal.

Hasil uji hipotesis menunjukkan diterima atau tidaknya hipotesis yang telah diajukan oleh peneliti. Uji hipotesis pada penelitian ini menggunakan analisis regresi linier sederhana untuk mengetahui pengaruh penggunaan media pembelajaran terhadap hasil belajar siswa pada pembelajaran matematika.

Untuk melihat bagaimana pengaruh penggunaan media power point terhadap hasil belajardengan menggunakan program komputer SPSS Analisisnya dilakukan sebagaimana berikut:

Tabel 7. Hasil Koefisien Determinan

\begin{tabular}{lcrrr}
\hline Model & R & R Square & $\begin{array}{r}\text { Adjusted R } \\
\text { Square }\end{array}$ & $\begin{array}{l}\text { Std. Error of } \\
\text { the } \\
\text { Estimate }\end{array}$ \\
\hline 1 & $\begin{array}{l}.343 \\
\mathrm{a}\end{array}$ & .118 & .097 & 1.705 \\
\hline
\end{tabular}

Kemudian untuk melihat kontribusi penggunaan media power point mempengaruhi hasil belajar siswa, dapat digunakan rumus Koefisien Penentu (KP) atau Koefisien Determinasi yang dirumuskan $K D=r^{2} \cdot 100 \%=0,118 \cdot 100 \%=11,8 \%$, artinya penggunaan media power point memberikan kontribusi terhadap hasil belajar siswa sebesar $11,8 \%$ atau dapat disimpulkan hasil belajar siswa dipengaruhi oleh penggunaan media power point sebesar 11,8\%.

Tabel 8. Koefisien Persamaan Garis Regresi

\begin{tabular}{|c|c|c|c|c|}
\hline \multirow[t]{2}{*}{ Model } & $\begin{array}{l}\text { Unstandardized } \\
\text { Coefficients }\end{array}$ & $\begin{array}{l}\text { Standardi } \\
\text { zed } \\
\text { Coefficien } \\
\text { ts }\end{array}$ & \multirow[t]{2}{*}{$\mathrm{T}$} & \multirow[t]{2}{*}{ Sig. } \\
\hline & Std. Error & $\begin{array}{c}\text { Bet } \\
\mathrm{a}\end{array}$ & & \\
\hline
\end{tabular}




\begin{tabular}{llrlrrr}
\hline 1 & (Constant) & 82.070 & 1.376 & & 59.623 & .000 \\
\hline $\begin{array}{l}\text { MEDIA POWER } \\
\text { POINT }\end{array}$ & .138 & .057 & & .343 & 2.396 & .021 \\
\hline
\end{tabular}

Persamaan regresi pada pengaruh penggunaan media power point terhadap hasil belajar siswa adalah $\mathrm{Y}=\mathrm{a}+\mathrm{bX}$ yaitu $\mathrm{Y}=82,070+0,343 \mathrm{X}$, yang berarti penggunaan media power point berpengaruh positif terhadap hasil belajar siswa.

Perumusan hipotesis tentang penggunaan media gambar terhadap hasil belajar siswa adalah sebagai berikut:

$\mathrm{H}_{0} \quad$ : Tidak ada pengaruh yang signifikan antara penggunaan media power point terhadap hasil belajar siswa pada pembelajaran matematika di SMAN 17 Makassar.

$\mathrm{H}_{1} \quad$ : Ada pengaruh yang signifikan antara penggunaan media power point terhadap hasil belajar siswa pada pembelajaran matematika di SMAN 17 Makassar.

Berdasarkan tabel diatas Output Coefficients, terbaca bahwa nilai $t_{\text {hitung }}$ sebesar $=2,396$ dengan taraf nilai sign 0,021 untuk penggunaan media power point. Sedangkan untuk menguji hipotesis yang diajukan diterima atau ditolak dengan nilai t-test dan taraf sig. Ketentuan penerimaan atau penolakan terjadi jika $t_{\text {hitung }}>\mathrm{t}_{\text {tabel }}$ maka $\mathrm{H}_{0}$ ditolak dan $\mathrm{H}_{1}$ diterima, dan jika nilai $s i g \leq 0,05$, maka $\mathrm{H}_{0}$ ditolak dan $\mathrm{H}_{1}$ diterima. Sebelum membandingkan $\mathrm{t}_{\text {tabel }}$ dan $\mathrm{t}_{\text {hitung }}$ terlebih dahulu mencari nilai $t_{\text {tabel }}$ dengan derajat kebebasan $\left.\mathrm{df}=/ 2: \mathrm{n}-\mathrm{k}-1\right)$ atau $(0,05 / 2: 45-1-1)$ maka diperoleh nilai $t_{\text {tabel }}$ sebesar 2,017.

Dilihat dari tabel Coefficients, didapat nilai $t_{\text {hitung }}=2,396>t_{\text {tabel }}=2,017$ dan taraf $s i g=0,021<$ 0,05 sehingga dapat ditarik kesimpulan bahwa menolak $\mathrm{H}_{0}$ dan menerima $\mathrm{H}_{1}$ ada pengaruh yang signifikan antara penggunaan media gambar terhadap hasil belajar siswa pada pembelajaran matematika di SMAN 17 Makassar.

\section{Pembahasan}

Pengaruh Penggunaan Media Pembelajaran Power Point terhadap Hasil Belajar Siswa pada Pembelajaran matematika di SMAN 17 Makassar berdasarkan penyajian data dan analisis data, menunjukkan bahwa power point sebagai media pembelajaran memberikan pengaruh yang signifikan terhadap hasil belajar siswa pada pembelajaran Pendidikan matematika di SMAN 17 Makassar. Dari hasil uji t dapat diketahui bahwa pengujian hipotesis alternatif $\left(\mathrm{H}_{1}\right)$ pertama diterima. Pengujian hipotesis pertama dilakukan dengan cara membandingkan antara hasil dari thitung dengan ttabel. Dari tabel Coefficients di atas diperoleh nilai thitung = 2,396. Sementara itu, untuk ttabel dengan taraf signifikansi 0,05 diperoleh nilai ttabel $=2,017$. Perbandingan antara keduanya menghasilkan: $t_{\text {hitung }}>t_{\text {tabel }}(2,396>2,017)$. Nilai signifikansi $t$ untuk variabel penggunaan media power point adalah 0,021 dan nilai tersebut lebih kecil dari pada probabilitas $0.05(0,021<0,05)$. Sehingga dalam pengujian ini menunjukkan bahwa $\mathrm{H}_{1}$ 
diterima dan $\mathrm{H}_{0}$ ditolak. Hal ini berarti bahwa ada pengaruh yang positif dan signifikan antara penggunaan media pembelajaran power point terhadap hasil belajar siswa pada pembelajaran matematika di SMAN 17 Makassar. Hasil penelitian ini, sesuai dengan teori yang dikemukakan oleh Schramm dalam Rudi dan Cepi bahwa media pembelajaran teknologi pembawa pesan yang dapat dimanfaatkan untuk keperluan pembelajaran. 20 Guna untuk mencapai tujuan pembelajaran tertentu. Djamarah dan Zain dalam bukunya menegaskan, bahwa:

Media pembelajaran adalah alat bantu apa saja yang dapat dijadikan sebagai penyalur pesan agar tercapai tujuan pembelajaran.

Pemilihan media pembelajaran yang tepat dapat menjadikan proses belajar mengajar menjadi lebih aktif, efektif dan dapat memicu semangat belajar siswa. Salah satu media pembelajaran yang dapat membantu merangsang siswa untuk mengetahui lebih jauh materi pembelajaran yaitu media pembelajaran power point. Power point adalah salah satu program aplikasi atau software yang dirancang khusus untuk mampu menampilkan program multimedia dengan menarik, mudah dalam pembuatan, mudah dalam penggunaan, dan relatif murah. Microsoft power point selangkah lebih maju dibanding drill and practice, karena Microsoft Power Point tidak hanya menampilkan informasi, tetapi juga memberikan gambaran kepada siswa melalui proses pembelajaran. Dengan demikian akan menarik perhatian siswa sehingga siswa memperhatikan penyampaian materi yang diberikan oleh guru. Seperti yang dikemukakan oleh Mardi dkk dalam bukunya bahwa:

Media power point adalah salah satu program aplikasi dari microsoft yang dapat digunakan untuk melakukan presentasi, baik untuk melakukan sebuah rapat maupun perencanaan kegiatan lain termasuk digunakan sebagai media pembelajaran di sekolah.

Media power point merupakan suatu aplikasi yang digunakan untuk memfasilitasi pembelajaran di kelas dan memiliki potensi mengajar siswa yang tidak memiliki guru qualified dalam penguasaan materi. Dengan menggunakan media power point dalam pembelajaran akan membantu siswa dan guru dalam memahami topik yang belum dikuasainya. Hal ini sejalan dengan pendapat yang dikemukakan oleh Herlanti dalam Munadi dalam bukunya bahwa:

Media power point mempunyai beberapa keunggulan diantaranya, (1) Mampu menampilkan objek-objek yang sebenarnya tidak ada secara fisik atau diistilahkan dengan imagery. Secara kognitif pembelajaran dengan menggunakan mental imagery akan meningkatkan retensi siswa dalam mengingat materi-materi pelajaran, (2) Mampu mengembangkan materi pembelajaran terutama membaca dan mendengarkan secara mudah, (3) Memiliki kemampuan dalam mengabungkan semua unsur media seperti teks, gambar, video, grafik, tabel suara dan animasi menjadi satu kesatuan penyajian yang terintegrasi, (4) Dapat mengakomodasi peserta didik sesuai dengan modalitas belajarnya terutama bagi mereka yang memiliki tipe visual, auditif, kinestetik, atau yang lainnya.

Terdapat pendapat lain yang senada, yaitu pendapat yang dikemukakan oleh Wati dalam bukunya, bahwa: 
Media power point mempunyai beberapa kelebihan diantaranya, (1) Tampilannya menarik dan dilengkapi dengan permainan warna, huruf, animasi, teks, dan gambar atau foto, (2) Mampu merangsang siswa untuk mengetahui lebih jauh informasi mengenai materi yang tersaji, (3) Tampilan visual mudah dipahami, (4) Membantu atau mempermudah guru dalam proses belajar mengajar, (5) Mudah dipahami, (6) Bisa menampilkan gambar, grafik atau diagram, (7) Bersifat kondisional, (8) Praktis.

Dengan demikian media pembelajaran power point memiliki peran penting dalam merangsang siswa memahami materi pelajaran. Karena kecanggihannya media power point dapat mempermudah para pendidik dapat dengan mudah menyampaikan materi pembelajaran dengan menarik sehingga tercipta pembelajaran yang aktif dan menyenangkan. Seiring perkembangan kemajuan teknologi yang sangat berpengaruh terhadap perkembangan pendidikan di sekolah, maka penggunaan media pembelajaran sangat dianjurkan

Berdasarkan teori-teori diatas dapat dilihat bahwa penggunaan media pembelajaran dalam menentukan tingkat pencapaian tujuan pembelajaran sangat lah berperan penting. Media pembelajaran power point merupakan media yang dapat merangsang siswa untuk mengetahui materi pelajaran secara lebih jauh dan memfokuskan siswa pada prose pembelajaran serta membantu guru dalam proses belajar mengajar. Siswa yang fokus dan juga paham akan materi pembelajaran akan sangat membantu siswa untuk mengingat mengenai materi yang telah disampaikan oleh guru sehingga secara tidak langsung hasil belajar pun juga akan terpengaruh.

Dengan demikian hasil belajar siswa dapat dengan mudah meningkat karena siswa telah fokus dalam mengikuti pembelajaran sehingga siswa mempunyai ingatan yang kuat terhadap materi pelajaran, selain itu siswa akan mudah memahami materi sebab media power point memiliki tampilan visual yang mudah dipahami, tujuan pendidikan yang telah direncanakan bisa tercapai. Seperti yang dikemukakan oleh Purwanto dalam bukunya, bahwa: Hasil belajar merupakan pencapaian pencapaian

Hasil belajar merupakan pencapaian pencapaian tujuan pendidikan pada siswa yang mengikuti proses belajar mengajar. Hasil belajar adalah perubahan yang mengakibatkan manusia berubah dalam sikap dan tingkah lakunya. Hubungan antara media pembelajaran power point dengan hasil belajar siswa pada pembelajaran matematika sangatlah jelas karena hasil belajar siswa yang tinggi tidak akan didapat apabila tanpa proses penyampaian materi dengan menggunakan media pembelajaran power point. Media power point juga dapat merangsang siswa untuk mengetahui lebih jauh tentang materi pembelajaran. Media power point juga mampu memudahkan siswa memahami materi pelajaran karena tampilan visualnya yang mudah dipahami Jadi, seorang siswa tidak sepenuhnya dapat memahami pelajaran matematika. Dengan adanya penggunaan media pembelajaran power point, dapat membantu memahamkan siswa tentang isi pelajaran, memperjelas suatu masalah yang siswa belum paham dan merangsang siswa untuk mengetahui materi pelajaran secara lebih jauh. 


\section{PENUTUP}

\section{Kesimpulan}

Ada pengaruh yang signifikan antara penggunaan media pembelajaran power point terhadap hasil belajar siswa pada pembelajaran matematika di SMAN 17 Makassar yang ditunjukkan dari $t_{\text {hitung }}>t_{\text {tabel }}(2,396>2,017)$. Nilai signifikansi $t$ untuk variabel penerapan model diskusi pemahaman teks adalah 0,021 dan nilai tersebut lebih kecil dari pada probabilitas 0,021 $(0,021<$ 0,05). Dengan demikian, pengujian menunjukkan $\mathrm{H}_{\mathrm{o}}$ ditolak $\mathrm{H}_{1}$ diterima. Oleh karena itu, dapat disimpulkan dari hasil tersebut yang memperlihatkan bahwa terdapat pengaruh yang signifikan antara penggunaan media pembelajaran power point terhadap hasil belajar siswa pada pembelajaran matematika di SMAN 17 Makassar

\section{Saran}

Berdasarkan penelitian yang dilakukan diharapkan agar pembelajaran dengan menggunakan media pembelajaran power point dapat dikembangkan lagi.

\section{DAFTAR PUSTAKA}

Asyar, Rayandra. 2012. Kreatif Mengembangkan Media Pembelajaran. Jakarta: Gaung Persada Press.

Hasan, M. Iqbal. 2012. Pokok-Pokok Materi Statistik 2 (Statistik Inferensif). Jakarta: Bumi Aksara.

Rusman. 2012. Belajar dan Pembelajaran Berbasis Komputer Mengembangkan Profesionalisme Guru Abad 21. Bandung: Alfabeta.

Sadiman, Arif S, dkk. 2012. Media Pendidikan. Jakarta: PT Raja Grafindo Persada 